\title{
Uma leitura do filme Vou para casa, de Manoel de Oliveira
}

Celia Cavalheiro Universidade do Senac

“-Mas que país mais lento, esse de onde você veio!comentou a Rainha, com um certo desprezo.

- Mas por aqui, é como você vê. É necessário correr e mais correr com o máximo de velocidade, somente para permanecer no mesmo lugar. Se você quiser chegar a algum outro ponto, deverá correr pelo menos com o dobro de velocidade!"

Lewis Carrol - Alice no Pais do Espelho

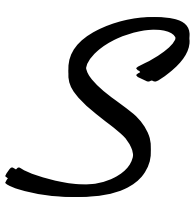

obre o filme de Manoel de Oliveira "Vou para casa", poderíamos simplesmente dizer que trata-se de uma metáfora sobre a impossibilidade do ser humano de sair de dentro de sua própria concha, e que o mover-se é um esboço dos modos de retornar ao lar, a si mesmo, ao coração das emoções. Que, como explica a Rainha louca do sonho de Alice, é necessário correr o dobro para se chegar a um passo de distância, lugar privilegiado de onde assistiríamos ao nosso próprio esforço para depois constatar que não, não nos movemos. Estaremos sempre no lugar de espectadores da tentativa constante de se chegar a algum lugar. $\mathrm{O}$ movimento da vida, o tempo como um acontecimento inexorável, parece impulsionar a vontade humana em prol de algum heroísmo, mas as tragédias cotidianas nos devolvem ao nosso lugar natural, ou seja, à nossa condição de mônadas, soltas e adversas.

Mas o 'simplesmente' é que nos pega. A grande maestria do diretor português é justamente a de detalhar os grandes 
acontecimentos em sequências inteiras apoiadas apenas nos pequenos detalhes, gestos, olhares que se alongam sobre banalidades quaisquer; e extrair daí, da conformidade humana, o retrato da sobrevivência. Mas não uma sobrevivência comum, e sim aquela que se adquire com a maturidade. Para tanto os recursos são, como sempre, os mais caros a Manoel de Oliveira: o jogo de cena, o teatro, o homem como um incansável tradutor de sua alteridade - não é esta a função do ator? -, a vida como representação. O mote da história que assistimos é o da recuperação, por assim dizer, de um velho ator de teatro que, ao final de uma apresentação, recebe a notícia da morte de sua mulher, filha e genro num acidente de carro. Após o choque inicial ele vai lentamente tocando sua vida, cuidando do neto - o único parente que lhe sobra - e de seu trabalho no teatro. Até que recebe um convite para atuar em um telefilme com todos os ingredientes chamativos do mundo moderno: sexo, drogas e violência. Recusa veementemente o papel, porém, aceita trabalhar em uma outra produção para televisão, uma adaptação do famoso romance de Joyce, "Ulisses", onde faria o papel de Buck Mulligan. Mas, logo nos primeiros ensaios, não consegue se lembrar das falas, no esforço de rememoração fica nítida sua percepção do vazio, da falta de sentido da existência, e o ator se retira, informando apenas: "- Vou para casa".

A primeira imagem do filme é feita por uma câmera que focaliza o centro do palco onde está sendo encenada a peça de Eugène Ionesco, “O Rei está morrendo"1. A cena final mostra os últimos momentos, um pouco cômicos, de um rei em plena decadência física e moral, em seguida a câmera se desloca para

\footnotetext{
${ }^{1}$ Na peça de Eugène Ionesco, "Le Roi se Meurt", de 1962, cujo tema é o da fragilidade humana perante a iminência da morte, uma das principais questões levantadas pelo personagem, o Rei Bérenger é: "Se não era para sempre, porque é que eu nasci?"
} 
o canto superior do camarote, quando três homens chegam e se posicionam na pequena escada que dá para a platéia - como são três as mensageiras do destino: Cloto, Láquesis e Átropos ${ }^{2}$ - e ouvem, neste momento, a fala do Rei (interpretado pelo personagem protagonista Gilbert Valence): "- Já não posso ouvir, tenho medo!" para depois irem aguardar na coxia, um pouco impacientes, o final do espetáculo, quando será anunciada a notícia fatídica. E a fala que segue é:

"- Não tive tempo, não tive tempo, não tive tempo."

"- Vai acabar se resignando."

"-Eu nunca me resignei na vida."

"-Quem diz que não quer se resignar é sinal que vai resignar-se!" E a sentença:

"- O Rei já não está acima das leis. Pobre coitado, é um comum."

Personagem dentro do personagem, interpretação da interpretação, o rei de Ionesco, anuncia com veemência sua impossibilidade de acreditar nos homens, de ouvir qualquer conselho, está abismado com a certeza do fim. $\mathrm{O}$ ator que o interpreta não sabe o desfecho da sua própria história, daquilo que o aguarda no camarim, lugar comumente destinado a abrigar as glórias do final do espetáculo e que, neste dia, tomado pela imagem da tristeza e desconsolo - descrita no plano detalhe da silhueta de um cavalete despido das fantasias utilizadas - selará para sempre a incomunicabilidade do ator

\footnotetext{
${ }^{2}$ Destacamos a comparação mítica com as três Moiras: Cloto, a que tece o fio da vida, o fluxo da existência; Láquesis, a que tece o ritmo das glórias e derrotas dos mortais e Átropos, a que decide a duração da vida e não mede as palavras para predizer os últimos momentos. Pois o ritmo interno da história narrada no filme acompanha, com discreta precisão os momentos em que os laços se rompem e o homem vai cedendo ao seu destino.
} 
com o mundo real. No corte do "algum tempo depois", a transição feita de uma cena para outra, seguida de uma panorâmica pela cidade em sua luz diurna e seu movimento habitual de carros e transeuntes, é a tomada de uma cadeira vazia, na penumbra do quarto do ator, de frente a cortinas cerradas barrando o primeiro sol da manhã. Em seguida vemos aparecer a figura do velho que se aproxima da janela, com um certo vigor, afasta um dos lados da cortina e observa o neto que dá voltas em sua bicicleta pelo jardim, até receber o lanche de Guilhermina - a governanta - e ir para a escola. De novo a penumbra do quarto, o velho senta na cadeira e segura o porta retrato, olha a foto com tristeza e apóia a cabeça em uma das mãos. A cena é da desolação completa ${ }^{3}$, vemos uma cadeira e uma pequena mesa com objetos pessoais, iluminadas pela luz da manhã mas ainda imersas na penumbra do quarto, um abajur com uma lâmpada amarelada e a figura do velho sentado, apoiando a cabeça na sua mão esquerda. Ele sabe, e o espectador também, que este mundo cotidiano não mais lhe pertence, a imagem da inocência descompromissada da infância, que ainda não prevê as perdas e os acasos de toda uma vida, não lhe diz mais respeito, ao menos neste momento. E a partir daí assistiremos nosso personagem lidar com as pequenas coisas e, principalmente, participaremos de sua tentativa de se apegar a elas. O que fica, portanto, neste jogo de antagonismos representado pela penumbra de seu quarto e a luz do jardim, é o último conselho da Rainha na peça encenada, que o rei "não se curve, não se apóie na bengala - já que não a possui-, não se abaixe."

${ }^{3}$ Cena compatível à sequência do desenlace final de "Singularidades de uma rapariga loira", adaptação da novela de Eça de Queirós, realizada por Manoel de Oliveira, de 2009. A personagem principal, depois de descoberta sua 'perversão', é focalizada, numa longa tomada, largada numa poltrona, amargando o seu destino. 
E não há intenção exageradamente dramática nestas primeiras sequências, é como se o diretor simplesmente deslizasse sua câmera pelos acontecimentos sem interferência intelectual, ou seja, os fatos são os fatos dados pelos acontecimentos inevitáveis, veremos o que se passa com a vida que resta agora. Esta é a grande introdução do filme, e esta introdução se alonga de tal maneira acabando por forçar uma quebra estrutural na narrativa, na medida em que ainda estaremos nos familiarizando com este personagem no mais avançado da história. Porque é assim com o sofrimento, nunca nos acostumamos de fato a ele. Portanto, apesar de estar valendo aqui uma narrativa fílmica clássica: introdução; desenvolvimento -incluindo aí o elemento 'complicador' no convite ao trabalho para a televisão-e o desenlace; é no estilo, no 'modo de fazer' do realizador, ao não permitir muitas reverências a uma tal análise estrutural clássica, que sua intenção se revela. E a intenção, fica claro, é anunciar o prolongamento da dor na obrigação da continuidade da vida e, para tanto, não basta contar uma história, modo óbvio de não estar presente, mas consumi-la, sem estratégias até o final. Ousamos então entender este filme sem os movimentos clássicos de desenvolvimento e desenlace, mas apenas como o todo que se estica: um único passo adiante depois de muito correr.

Mas Manoel de Oliveira não é exatamente um cineasta do pessimismo, em seus filmes, mesmo nos momentos mais dramáticos, não está assegurado o sofrimento como expiação da alma ou redenção; nem mesmo como denúncia de uma época. Aspectos encontrados em cineastas mais afeitos a uma postura comprometida, seja com aborrecimentos insuperáveis de um século aturdido por sérias questões de ordem política 
e moral, seja por uma vanguarda estilística ${ }^{4}$. Ao contrário, em quase todas as decisões do cineasta português encontramos um cristianismo meio primitivo, nem exacerbado nem tão pouco comprometido com a noção de culpa e sofrimento. A fé e a esperança prevalecem sem nenhuma pieguice ao provar no homem o espírito apaziguador no seu eterno caminhar entre a dúvida e a fé. No todo de sua obra, poderíamos nos remeter desde a realização de Acto de Primavera (1963), onde há uma verdadeira sagração da paixão de Cristo, até Viagem ao Princípio do Mundo (1997), quando o homem, ser finito e inacabado, ao visitar a sua morada mais antiga é ressuscitado, metaforicamente, de toda a sua tragédia pessoal. E, mesmo em finais mais perturbadores como a explosão do navio na última sequência de Filme Falado (2003), encontramos um assunto já resolvido: mãe e filha perdem os botes salva-vidas porque estavam resgatando afetos. $\mathrm{O}$ fato político-social da bomba colocada ali não gera uma reflexão sobre o sacrifício das duas personagens; mas sobre a fatalidade, o destino. Afinal, acabaremos concluindo que as tragédias não são deslocamentos, são vias de acesso que nos reconduzem ao lugar natural, ou seja, de volta para casa.

Neste sentido, é representativo o modo como a 'normalidade' é restabelecida na vida do ator em Vou para Casa. Ele é mostrado andando pelas ruas, olhando vitrines, sendo reconhecido - pedem-lhe autógrafos - até entrar em uma loja de sapatos e sair de lá calçando um par novo, de cor amarelada, reluzente. Satisfeito com a própria compra entra num café e

${ }^{4}$ Referimo-nos aqui principalmente aos cineastas italianos do pósneorealismo e, em particular, ao olhar de acentuado existencialismo encontrado em filmes como Dois Destinos (1962) e A Primeira Noite de Tranquilidade (1972), de Valerio Zurlini, onde a felicidade, se existe, parece pairar muito além do merecimento humano. 
folheia seu jornal, há uma espécie de dança marcada neste café, que é mostrada mais de uma vez, ao sair de sua mesa outro sujeito chega e cumpre também seu ritual. As coisas repetidas, habituais marcadas pela aquisição do sapato novo, que poderia levá-lo a uma nova vida. Anoitece e o corte é feito para o personagem novamente no palco, desta vez a peça interpretada é de Shakespeare: $A$ Tempestade, e a fala que se destaca vai explicando a disposição do personagem:

“- Nossa pequena festa terminou. E nossos atores, como eu the disse, eram todos espíritos que se evaporaram no ar leve. E como esta visão que era toda imaterial (...) o vasto globo e todos que aí amam e vivem, tudo se dissipará como essa sombra de espetáculo, não deixando de si nem o menor rastro. Nós somos feitos da mesma matéria dos sonhos."

Em seguida, deparamos com a sequência mais inusitada. Num corte meio abrupto o espectador ouve uma conversa entre o velho ator e seu agente, enquanto assiste ao movimento dos pés calçados pelo sapato novo ${ }^{5}$ :

"- Como você se sente?

- Muito bem. Eles são muito confortáveis.

- Parece radiante com os sapatos...

- Sim, sim.

- Mas não era disso que eu falava, estava perguntando como você se sente depois da morte da tua mulher e filha.

- Eu vivo ... eu vivo com a minha solidão."

${ }^{5} \mathrm{O}$ cineasta e crítico de cinema Eduardo Valente comenta, em seu texto sobre o filme, publicado na revista Contracampo, 2001, n. 31-32 (www.contracampo.com.br), sobre os enquadramentos de Manoel de Oliveira "que nos deixam minutos a fio a observar um sapato, talvez o sapato mais dramático da história do cinema." 
E a conversa segue, sempre com a câmera direcionada nos pés do ator, só no final a câmera sobe em plano americano, o amigo sugere que ele arrume uma nova companhia, ele se ressente da falta de sutileza do agente. Os dois se despedem e, ao andar sozinho pela rua, ele é assaltado por um rapaz sob a ameaça de uma seringa contaminada, fica sem o paletó, o relógio e o par de sapatos novos. Volta só de meias para casa. Todos os elementos são significativos, há uma tentativa explícita, mas muito delicada, de recomposição da felicidade, ou, ao menos, de uma certa satisfação, que é rapidamente malograda com o assalto, deixando novamente o vazio, a solidão. Na reunião do dia seguinte, calçando os sapatos antigos, ele recusa, ofendido, o convite para o seriado da televisão. Depois caminha pelas ruas de Paris como um turista em sua própria cidade, observando as coisas, olhando para o alto. Compra um novo par de sapatos, igual ao anterior, faz outras compras, um presente para o neto, vai buscá-lo na escola, brincam juntos com os carrinhos de controle remoto. Corte para uma nova tomada da janela do quarto, ao amanhecer: ele observa o neto, olha para a mesa, apanha o porta-retrato, mas já não se senta - não se curva - e segue o seu dia, aparentemente sem ter muito mais tempo, ou disposição para a tristeza.

Parece que houve um avanço, o 'desenlace' através da recomposição das singularidades de sua vida, seu trabalho. E quase nos enganamos ao seguirmos, um tanto aliviados, a trajetória daquele personagem pacífico, porém decidido. Mas Manoel de Oliveira conduz esse desdobramento até o limite da transformação, estica a corda da nossa percepção até o ponto em que fica claro que tudo não passava de possibilidades. A vida que se queria ali, exemplificada na disposição do velho ator, assim como a narrativa coerente, reta e confortável que o filme parece proporcionar, não passa de uma hipótese, de uma 
situação desejável. Assim como o sapato novo representa, descaradamente, a idéia de um novo caminho, o aceite para outro convite - desta vez uma adaptação de Joyce, no papel de Buck Mulligan, oferta muito mais digna - provocará a ilusão de que as coisas finalmente tomaram um rumo, como se desprendessem do peso da tragédia. E é neste ponto que o diretor português, usando ainda o recurso da cena exposta, da composição do personagem sobre o personagem - o ator é mostrado sendo maquiado, caracterizado para a gravação que marcaria uma novidade em sua carreira - vai retirando, uma a uma, todas as camadas de uma continuidade viável. Ao focalizar demoradamente a caracterização do personagem, o filme deixa claro também a fragilidade do ator, cujos olhos não possuem mais a vivacidade da primeira vez que o vemos em cena.

Os ensaios, as gravações no estúdio não dão certo, ele esquece as falas e suas tentativas são assistidas pelo olhar compreensivo do estrangeiro - o realizador da série é um americano (interpretado por John Malkovich) - outro ponto que explora a referência ao outro, ao mundo externo, a uma reintegração à sociedade. E, como num banho de água fria, o espectador percebe que a situação é a mesma do início, no momento da notícia da tragédia. Foi naquele tempo a grande transformação, o resto não passaria de engodo, uma simulação, como no teatro. Mesmo porque, na sequência da conversa com o agente, no café, ele já havia dito que era um ator e, como tal, "estava sempre na pele de outro personagem". A maestria do filme está em fazer o espectador se esquecer disto e acreditar numa narrativa linear, com um sentido edificante. Demoramos um pouco para perceber que não saímos do lugar, no máximo, estamos a um passo de distância. 
Gilbert Valence, o velho ator golpeado fatalmente pelo destino, por um mau destino, é focalizado como se aceitasse as coisas, como se acatasse, não sem tristeza, os acasos, as adversidades, as ditas anomalias da vida. Num primeiro olhar, aquele do engodo, diríamos que ele segue, com afinco, os preceitos do próprio cineasta, sua crença inabalável no destino e nos desígnios divinos. Torna-se seu alter ego na resignação e busca incansável, senão da felicidade estridente, da satisfação, da completude nas obras e afazeres reinventados a cada momento. Mas há, no personagem, uma negação da realidade, um passar por cima do sofrimento, então a resignação é uma espécie de farsa e isto precisa ser resolvido.

Em várias entrevistas e depoimentos, sempre que o interlocutor lhe dá a oportunidade, Manoel de Oliveira afirma coisas como "... a natureza e o destino estão na mão de Deus, e Deus existe. Porque se existe criatura terá de haver um Criador. Tudo é como é e não há o que responder. É somente como católico que tenho a resposta: creio em Deus." ${ }^{16}$ Por isto, não 'desconstruiria' à toa, ou por mero capricho, as tentativas de seu personagem de retomar a normalidade em seu lar, em seu trabalho. Se, no final, o velho ator sai de cena, ainda com as roupas e maquiagem do personagem recém encarnado, e anda pelas ruas repetindo falas desconexas, talvez seja para mostrálo finalmente despido da possibilidade de interpretação, de viver o outro e escamotear a própria vida. Ao entrar em sua casa com pouquíssima noção da realidade e ser seguido pelo olhar assustado, entristecido, mas também repleto de compreensão, do neto - que, agora ele, menino, apercebe-se da terrível notícia,

${ }^{6}$ MACHADO, 2005, p. 47. Entrevista concedida a Leon Cakoff. 
acaba de ser visitado pelo acaso, ao constatar que seu velho avô, que lhe servia de escudo para as desgraças, também estava de partida. Tudo somado, já é prova suficiente da extensão da fragilidade humana, da inutilidade e, acima de tudo, perversidade do sentido da palavra ' $n \tilde{a} o^{\prime}$, tanto como recusa inútil dos acontecimentos, como representação deslocada, fora de cena.

Sabe-se como é cara ao diretor a reflexão de Padre Vieira: “Terrível palavra é o non: por qualquer lado que lhe pegueis é sempre non."7 Esta imagem é a medida de todas as impossibilidades, das portas inexoravelmente fechadas, da desistência completa e do abandono. Por isto seu personagem, ao dizer não ao sofrimento completo e ir tocando o cotidiano, passa a viver uma vida de mentira, a incorporar cada vez mais a atitude de seus personagens, até vivenciar a experiência de não estar mais em seu lugar. Representada pela 'nova' possibilidade de trabalhar na televisão - lugar de repetição e retoques que vulgarizam a dramatização em contraponto ao teatro, onde o privilégio das emoções depende da incorporação do texto, da fala, do gesto - na tentativa de sair da rotina, de viver mais no raso, cogitar um status, uma mecanicidade nunca antes sonhados, aquele velho, personagem de si mesmo, se perde numa lucidez nunca experimentada, ele não estava preparado para a realidade.

Que maior distanciamento poderia haver entre esta fórmula, ao mesmo tempo despojada e criteriosa de filmar, daquela que se propõe engajada, querendo a todo custo aprisionar o olhar do espectador para um ponto de vista único, o das intenções? O cinema de Manoel de Oliveira é rebuscado e também maroto e embusteiro, tendo sempre como critério a

${ }^{7}$ MACHADO, 2005, p. 49. 
verdade, mas jamais transformando esta coisa num projeto de fácil acesso. A vaidade impede o discernimento, e o homem, disto se vale o demônio, é sua presa eterna. Só um profundo conhecedor do outro lado, da condição do bem, poderia manipular esta fraqueza no humano e transformá-la em aprendizado. Reverter a vaidade humana, que sustenta a crença na superação da dor, em sabedoria criada no sofrimento, ou seja, relevância absoluta a todo e qualquer acontecimento no decorrer da existência. Daí a importância de focalizar uma história linear, uma narrativa clássica através da lentidão de imagens aparentemente sem significado, em cenas rompidas antes de uma conclusão sequencial, alongamento, como já dissemos, da perspectiva do personagem, de sua apresentação, sem passo seguinte.

Na imagem do velho atordoado que volta para casa como para um abrigo, podemos traduzir a sentença do personagem de Ionesco sobre o rei, 'pobre coitado', não estar mais acima da lei. $\mathrm{O}$ ator já não pode mais se refugiar em seus personagens, é um comum, vai ter que se haver com suas próprias desgraças, não paira mais sobre si mesmo. Tiradas todas as devidas camadas, é um mortal.

\section{Bibliografia}

ANDRADE, Sérgio. Ao Correr do Tempo - Duas Décadas com Manoel de Oliveira. Lisboa: Portugália Editora, 2008.

BERNARDET, Jean-Claude. O Declínio do Autor. In: O Autor no Cinema. São Paulo: Brasiliense, 1994, p. 153.

BURCH, Noel. Práxis do Cinema. São Paulo: Perspectiva, 1992.

HESIODO. Teogonia - A Origem dos Deuses. São Paulo: Iluminuras, 2001. 
IONESCO, Eugène. Le roi se meurt. Paris, Librairie Larousse, 1989.

MACHADO, Alvaro (Org.). Manoel de Oliveira. Mostra. São Paulo: Cosac Naify, 2005.

XAVIER, Ismail. O Discurso Cinematográfico: A Opacidade e a Transparência. 3. ed. revista e ampliada. Rio de Janeiro: Paz e Terra, 2005.

XAVIER, Ismail. Do texto ao filme: a trama, a cena e a construção do olhar no cinema. In: PELLEGRINI, Tânia et al. Literatura, Cinema e Televisão. São Paulo: Senac/Itaú Cultural, 2003.

\section{Catálogo}

M.O. Manoel de Oliveira. Porto: Museu Serralves/Civilização Editora. 1/3 Editora. Jul-Set. 2008.

\section{Resumo}

Uma leitura do filme Vou Para Casa, de Manoel de Oliveira, como uma metáfora da impossibilidade do ser humano de se distanciar de si mesmo, recorrendo eternamente à imagem da 'volta a casa', como um modo de sobrevivência perante as adversidades da vida. Sob a ótica de temas frequentes na obra do diretor, como a questão do jogo de cena, a herança teatral, servindo de apoio a diferentes enfoques para a estrutura narrativa cinematográfica. A análise trata também da postura do homem perante as tragédias pessoais e sua necessidade de se desvencilhar da realidade, protegendo-se nas camadas das diversas personalidades assumidas. 


\section{Abstract}

A reading of Manuel de Oliveira's Vou Pra Casa as a metaphor for the impossibility of human beings to distance themselves from their own life, eternally recurring to the image of 'going home' as a way of surviving before the adversities of life. Usual themes of the director work like the mise-en-scène and the theatrical request, serves the purpose of supporting different focus of the cinematography structure. The analysis also deals in such as the posture of men thrown before personal tragedy and its need to shake off reality guarding himself in different personae. 